\title{
John Scott Haldane, C.H., M.A., M.D., LL.D., F.R.S.
}

BY the death of John Scott Haldane at midnight on March I4, at the age of seventy-five, the biological sciences have lost a leader in thought and in research, a man of strong personality, and one whose influence in pure and applied science will pass down to posterity.

Scientist and philosopher, an unusual enough combination, Haldane possessed uncanny powers of observation and a flair for experimentation. His contributions to physiological knowledge, especially those relating to respiratory mechanisms, will remain for all time as landmarks in the particular fields he explored. As an applied physiologist his activities included the nature and physiological effects of gases in coal-mines, the cause of colliery explosions, caisson disease, deep diving, the ventilation of tunnels, and sunstroke among oil workers. Important as these researches were, Haldane's genius will be remembered chiefly for the breadth of his views on the nature of life, and for the philosophical outlook which was reflected in all his writings. Essentially interested in human physiology, Haldane's careful observations on Man led him to conclude that, although the external and internal environment may be interpreted in terms of the physical sciences, the phenomena of life are the expressions of the inseparable and co-ordinated relationships between the dynamic organisation of living tissues and their environment. In considering life "the physical and chemical picture is entirely obliterated by the organism." The descriptions of his investigations on Man, illuminated in their interpretation by his remarkable capacity for deductive and inductive reasoning, have been the foremost influence during the present century in redirecting attention towards the study of the animal as a whole. No less important has been the impetus which this work has given to the teaching of human physiology in medical schools. The Silliman Lectures given at Yale University in 1916 were published in a volume entitled Respiration. Few works have received greater attention or have been more widely read, and this classic, for such it is, will remain the foundation for newer conceptions of respiratory function for many years to come.

A concise and stimulating writer, Haldane was hardly less inspiring in discussion, although as lecturer he was not always easy to follow. Those who had the privilege of hearing him expand on his favourite topic-the philosophical basis of biology-or of listening to a critical 
analysis of some experimental work, were never for a moment deceived by his somewhat halting manner of speech. He always went straight to the root of the problem in a remarkably short space of time, and many will remember how frequently the crucial point in his argument would be made following a lengthy pause and accompanied by the short laugh and attractive smile which endeared him to all.

A courteous gentleman, a genius who understood and sympathised with the limitations of the less fortunate, and one whose insight into the complexities of vital phenomena will only be fully revealed by the passage of time, his loss will be deeply mourned both by physiology and medicine.

He was elected an Honorary Fellow of the Society in 1934.

See also Obituary Notices of Fellows of the Royal Society, vol. ii, No. $5,1936$.

I. de B. D. 